Laser Chem. 1988, Vol. 9, pp. 75-106

(C) 1988 Harwood Academic Publishers GmbH

Photocopying permitted by license only

Reprints available directly from the Publisher

Printed in the United Kingdom

\title{
Making Light Work-Applications of Lasers to Chemical Production
}

\author{
PETER A. HACKETT \\ Laser Chemistry Group, National Research Council, Ottawa, Ontario \\ K1A OR6, Canada
}

(Received January 25, 1988; in final form March 9, 1988)

This review considers several applications of photochemistry to the synthesis of chemicals by industry. Factors relevant to the use of lasers by industry in the synthesis of specific chemicals are also considered.

KEY WORDS: Industrial use of lasers; photochemistry.

\section{INTRODUCTION}

Most chemical industry processes rely for feedstocks on the products of photochemical reactions. Yet almost none of these processes use photochemistry. This is because photochemical processing requires high space-time to product ratios. Fortunately we did not have to wait for photosynthesis, its fruits were there when we needed them.

In this review, we consider the role of photochemical methods in industry and assess the impact that lasers will have.

\section{INDUSTRIAL PHOTOCHEMISTRY}

There are many thousands of photochemical syntheses; yet, there are only a handful of industrial processes using photochemistry to produce chemicals. ${ }^{1}$ Moreover, experience has shown it usual that whenever a 
photochemist demonstrates an elegant synthesis of a particular compound the organic chemist rises to the challenge and develops a chain of synthetic steps to the same material. Almost without exception the elegant, photochemical route is displaced by the conventional synthetic route. Recognizing this reality, we begin this section by a consideration of the disadvantages of photochemistry in the industrial environment. We then consider those few processes which have found industrial use.

\subsection{Disadvantages of photochemistry}

The prime disadvantage of photochemical processes is that, unlike photosynthesis, industrial processes use lamps. In industrial terms, lamps are expensive and difficult to scale to large throughput. This is because there is a practical limit to size of lamp which can be utilized; beyond this, throughput can only be increased by increasing the number of lamps. Thus, as with isotope separation using thermal diffusion columns, there are limited economies of scale.

Low pressure mercury lamps convert electrical energy into $253.7 \mathrm{~nm}$ photons with an efficiency of $60 \%$. ${ }^{2}$ However specific irradiances are low. The medium pressure mercury lamp is a brighter source. A $60 \mathrm{~kW}$ lamp costs around $\$ 1500$ and can be run for up to a year without significant reduction in output. ${ }^{1}$ Such lamps are $2 \mathrm{~m}$ long and $6 \mathrm{~cm}$ in diameter and once again the electrical to photon energy conversion efficiency is of the order of $50 \%$. However, the light is emitted on some 20 lines across the $200-600 \mathrm{~nm}$ spectrum. Addition of small amounts of thallium iodide shifts the emission spectrum such that a $60 \mathrm{~kW}$ lamp will radiate $13 \mathrm{~kW}$ at $535 \mathrm{~nm}$. The energy density available from these types of sources is low (approximately $0.5 \mathrm{~W}$ $\mathrm{cm}^{-2}$ at the lamp surface). Therefore, both the rate of processing and the density of processing will be low. Photons from these lamps are also expensive reagents. The energy and capital costs for $535 \mathrm{~nm}$ photons from the thallium doped lamp described above are 1.5 and 0.13 cents per einstein respectively. ${ }^{1}$

There are other disadvantages. Most organic molecules have broad absorption spectra. Often in order to prevent product photoreaction or other undesirable side reactions the lamps must be spectrally filtered. Sometimes product and starting material absorb in the same spectral regions and only photochemical equilibria not $100 \%$ conver- 
sion to products can be achieved e.g. Vitamin-D synthesis. ${ }^{3}$ Furthermore, the excited state is often an extremely fragile entity requiring high-purity, low-pressure, environments if energy degradation due to quenching is to be avoided.

Finally, in order to recover capital and energy costs all useful photons emitted from the lamp must be absorbed and used in the process. Cylindrical or point-source, lamp geometries require a rapidly increasing process volume as a function of the optical pathlength required to achieve total absorption. This limits the lower range of absorber concentration by absorption cross-section product that can be used. The upper limit to this product is governed by the local heating caused by photon absorption. The light absorption is necessarily inhomogeneous and this can cause problems in reactor design and operation. ${ }^{1}$

\subsection{Non-stoichiometric processes}

Photopolymerizations and free radical processes have several specific features which offset the disadvantages discussed above. The predominant is the large amplification of the quantum yield caused by long chain reactions. Industrial processes using photochemical initiation are grouped in Table I. ${ }^{1}$ The reader should note the wide variation in the throughput of these processes per watt of installed lamp power. This is a consequence of the wide range $(10,000-0.8)$ of quantum yields. Thermal free radical processes compete with the photochemical processes listed, particularly in the case of photochlorination. The photochemical methods offer the advantage of lower process temperatures which prevent many side reactions from occurring. They are particularly favoured over thermal initiation using thermally unstable initiators whenever extremely long chain lengths cannot be achieved.

\subsection{Stoichiometric reactions}

As a consequence of their reduced quantum yields $(\nless 1)$ stoichiometric photochemical reactions occupy a far smaller niche in the industrial sector. Their use has recently been reviewed by Martin Fischer. ${ }^{2}$ Clearly only high valued products are economically feasible. Apart from vitamin- $D_{3}$ synthesis, Table I, there are several other small scale processes. Among these are synthesis of; pharmaceuticals e.g. derivi- 
Table I Industrial application of photochemical synthesis ${ }^{\mathrm{a}}$.

\begin{tabular}{|c|c|c|}
\hline Reaction & Unit production ${ }^{\mathrm{b}}$ & Lamp $^{c}$ \\
\hline \multicolumn{3}{|c|}{ FREE RADICAL REACTIONS } \\
\hline $\begin{array}{l}\text { Photochlorination } \\
\mathrm{RH}+\mathrm{Cl}_{2} \stackrel{\mathrm{h} v}{\longrightarrow} \mathrm{RCl} \\
\mathrm{C}_{6} \mathrm{H}_{6}+\mathrm{Cl}_{2} \stackrel{\mathrm{h} v}{\longrightarrow} \mathrm{Cl}_{6} \mathrm{Cl}_{6} \\
\text { Toluene }+\mathrm{Cl}_{2} \stackrel{\mathrm{h} v}{\longrightarrow} \text { benzyl chloride, } \\
\\
\begin{array}{l}\text { benzyl dichloride } \\
\text { benzyl trichloride }\end{array}\end{array}$ & $\begin{array}{r}10,000 \mathrm{Mg} / \mathrm{a} \\
250 \mathrm{Mg} / \mathrm{a} \\
\sim\end{array}$ & $\begin{array}{l}7.5 \mathrm{~kW}(\mathrm{Hg}) \\
1.5 \mathrm{~kW}(\mathrm{Hg}) \\
\sim\end{array}$ \\
\hline $\begin{array}{l}\text { Sulfochlorination } \\
\mathrm{RH}+\mathrm{SO}_{2}+\mathrm{Cl}_{2} \stackrel{\mathrm{h} v}{\longrightarrow} \mathrm{RSO}_{2} \mathrm{Cl}+\mathrm{HCl}\end{array}$ & $250 \mathrm{Mg} / \mathrm{a}$ & $30 \mathrm{~W}(\mathrm{Hg})$ \\
\hline $\begin{array}{l}\text { Sulfoxidation } \\
\mathrm{RH}+\mathrm{SO}_{2}+\mathrm{O}_{2} \stackrel{\mathrm{h} v}{\longrightarrow} \mathrm{RSO}_{3} \mathrm{H} \\
\stackrel{\mathrm{NaOH}}{\longrightarrow} \mathrm{RSO}_{3} \mathrm{Na}\end{array}$ & $1600 \mathrm{Mg} / \mathrm{a}$ & $40 \mathrm{~kW}(\mathrm{Hg})$ \\
\hline 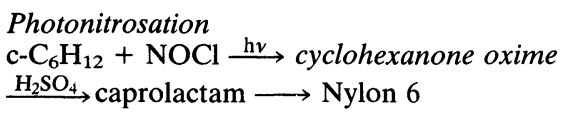 & $10,000 \mathrm{Mg} / \mathrm{a}$ & $3 \mathrm{MW}(\mathrm{Hg} / \mathrm{T} 1)$ \\
\hline $\begin{array}{l}\mathrm{cC}_{12} \mathrm{H}_{24}+\mathrm{NOCl} \stackrel{\mathrm{h} v}{\longrightarrow}-\mathrm{H}_{2} \mathrm{SO}_{4} \\
\text { cyclododecanone oxime } \\
\text { lauryllactam } \longrightarrow \text { Nylon-12 }\end{array}$ & $8000 \mathrm{Mg} / \mathrm{a}$ & $\approx 5 \mathrm{MW}(\mathrm{Hg}(\mathrm{T} 1))$ \\
\hline $\begin{array}{l}\text { 7-dehydrocholesterol } \stackrel{\mathrm{h} v}{\longrightarrow} \\
\text { Pre-vitamin- } D \stackrel{\text { heat }}{\longrightarrow} \\
\text { vitamin- } \mathrm{D}_{3} \\
\text { Other }^{\mathrm{e}}\end{array}$ & ACTIONS & $40 \mathrm{~kW}(\mathrm{Hg})$ \\
\hline
\end{tabular}

${ }^{\text {a }}$ After Reference 1.

b Annual production rate of underlined compound per production unit.

${ }^{c}$ Electrical consumption of lamps per production unit; $\mathrm{Hg}$ : medium pressure mercury lamp; $\mathrm{Hg} / \mathrm{T} 1$ : thallium iodide doped medium pressure mercury lamp.

d See Reference 1.

e Several small scale syntheses of pharmaceuticals, flavours, fragrances and radio isotopes, see text and reference 1 .

tized vitamin-D and vitamin-A acetate; fragrances e.g. rose oxide; and radiopharmaceuticals e.g. tritiated aldosterone via the Barton reaction. ${ }^{1}$

We conclude this section by mentioning the first photochemical isotope separation. The photochemical isotope separation of mercury, first suggested by Mrozowski in $1932,{ }^{4}$ was successfully demonstrated in 1953.5 A small market for mercury-196 was developed as it can be used as a spallation target to produce mercury-197. Mercury-197 is a suitable $\gamma$-emitter for use in brain scanning and cerebral blood flow 
measurements. In the late 60 's a small photochemical production facility for this isotope was established within the French nuclear industry. ${ }^{6} \mathrm{~A}$ monoisotopic mercury resonance lamp was used in conjunction with chemical trapping of the excited atoms by oxygen/ butadiene mixtures. Mercury-196 enriched to $50 \%$ (from $0.146 \%$ natural abundance) was produced at a rate of $10 \mathrm{~g}$ per year.

Isotope separation via photochemical methods was of seminal importance in developing laser chemistry. Most modern photochemists were trained using the text "Photochemistry" by Calvert and Pitts. ${ }^{7}$ At the close of a chapter discussing the interaction of light with atoms there is the following question:

What is the feasibility of effecting a photochemical enrichment of the ${ }^{235} \mathrm{U}$ isotope present in uranium which has this natural distribution of isotopes: ${ }^{235} \mathrm{U}, 0.71 \% ;{ }^{238} \mathrm{U}$, $99.29 \%$ ? Give your reasoning. If you consider such enrichment feasible, describe the experimental conditions under which you would attempt it.

This text was published six years after Maiman operated the first laser. After another 6 years, several readers had described feasible experiments.

\section{LASER PHOTOCHEMISTRY}

Having followed the discussion so far the reader will be aware that photochemical processing is of value only in processes with high quantum yield or in processes which produce high value products. I am sure that the reader will accept that lasers are no less expensive nor no more reliable than the lamps discussed above! Therefore, I accept the legitimacy of the question: what specific advantage can lasers bring to chemical processing? Answers to this question are rooted in the particular properties of laser radiation:

(1) Tunability: light of the precise wavelength for the most effective photochemistry can be delivered to the system. This property has its greatest benefit whenever the wavelength requirements are the more stringent e.g. isotope separate. When the frequency/bandwidth requirements are less severe e.g. selective organic photochemistry, lasers are sometimes found to be too selective.

(2) Intensity: radiation fields sufficiently intense to saturate atomic and molecular transitions are routinely available. Therefore, efficient 
multiphoton processes e.g. AVLIS (Atomic Vapour Laser Isotope Separation), MLIS (Molecular Laser Isotope Separation) vide infra, can be envisaged. Furthermore, highly non-equilibrium situations e.g. mole fraction of free radicals equal to one, can be achieved while the walls of the vessel remain cold.

(3) Divergence: light from laser sources can be made to propagate for long distances maintaining its cross-sectional area. Thus the light source can be removed from the chemical process. In conventional industrial photochemistry the lamp is intimately linked to the process (immersed in or surrounding the reactor). This means that servicing the light source is somewhat less involved for the laser (there may be more of it to do however). Remote operation has significant advantages for operation in severe environments e.g. radioactivity. The vitamin- $\mathrm{D}_{3}$ process for example involves intimate contact between $\mathrm{kW}$ light sources and large volumes of ether ${ }^{1}$ and this can present safety problems.

The low divergence propagation of lasers is fundamentally different to lamps. It allows a linear relationship between process volume and interaction length unlike the supralinear relationships for cylindrical and point sources. This immediately allows a wider range of absorber concentration by absorption cross-section product. Combined with suitably designed multipass cells, this suggests that lasers may ensure more homogeneous illumination of reaction volumes. This advantage will be the more significant for laser initiated free radical chains and for laser removal of ppm impurities.

Low divergence sources can be focussed to small spot sizes. Laser microchemistry, an area outside the scope of this review derives from this property. ${ }^{8}$

\subsection{Costing laser photons}

Clearly the advantages referred to above have their cost. Lasers are at an early stage of development and many are close to laboratory curiosities. When estimating the cost of a mature laser technology and a mature laser chemistry one necessarily has to resort to projection and process simulation. Before discussing this art, it is well to consider a few words of warning. Michael Klein put it this way in a review of computer simulation studies of solids. ${ }^{9}$ 
Nowadays, computer simulation is used routinely in fields as diverse as econometrics and meteorology. The successes that have been achieved to date are such that, whatever the field of application, a healthy scepticism is warranted in assessing the predictions based upon any particular computer model. In this respect, computer studies on 'real' systems, be they solid or liquid, have much in common with the modelling of the economy or the weather. That is, although in principle one can now obtain exact numerical results, we cannot thereby evade the question of how faithfully the model mimics reality.

Having disposed of the caveat, I will proceed to review several values for laser costs available in the recent literature. ${ }^{10-15}$ In developing laser costs one should consider at least the following issues: (1) capital costs and depreciation strategy; (2) maintenance cycles for all laser components based on realistic lifetime estimates; (3) operating costs based upon all consumables e.g. electricity and fuel gases; (4) personnel costs for operating and maintenance cycles; and (5) fixed costs e.g. space and interest charges. Research laser systems are dominated by the first component, particularly as the fourth item is never accounted. It is likely that mature process laser costs will be dominated by items two and four although designers of future systems may evolve high reliability systems whose costs are dominated by item three, a situation now pertaining to lamps. ${ }^{1}$

Davis estimates the integrated cost of photons from copper vapour laser pumped dye lasers required for uranium AVLIS to be in the range $\$ 36-360$ per kWh. ${ }^{10}$ Hall $^{11}$ and Kaldor and Woodin ${ }^{12}$ of Exxon Research and Engineering Company estimate the cost of photons from a $2 \%$ efficient $\mathrm{KrF}$ excimer laser at $\$ 34$ per $\mathrm{kWh}$ and $\$ 11$ per $\mathrm{kWh}$ from a $6 \%$ efficient $\mathrm{CO}_{2}$ laser. Ream estimates the capital cost of high average power $\mathrm{CO}_{2}$ lasers $(10 \mathrm{~kW})$ as $\$ 50$ per Watt. ${ }^{13}$ In a study of the costs of lasers for carbon-13 enrichment we developed costing procedures for $\mathrm{CO}_{2}$ and excimer lasers: ${ }^{14}$

Essentially the cost of photons can be divided into two major elements:

(a) some fraction of the total capital cost of the required laser system which is expected to be written off over a well defined period of time, and

(b) an average operating cost which takes into account labour, parts replacement, gas supplies, electricity, cooling requirements, etc.

Since both the UV and infrared systems are based on pulsed lasers, the operating cost it directly related to the number of pulses which can be delivered before various parts of the laser system fail or require maintenance. Thus it was necessary to establish a maintenance cycle for the replacement of optical components, energy storage capacitors, laser electrodes, power supply modules, recirculating fans and high voltage switches such as thyratrons or spark gaps. 
These considerations were based as much as possible on data which applied to presently available commercial lasers and resulted in photon costs of less than 50 cents/Einstein in the case of $\mathrm{CO}_{2}$ and tens of dollars/Einstein for a XeCl excimer laser. These approximate numbers clearly depend on several assumptions and would have to be determined with much greater precision if a plant of a particular capacity is subjected to a complete costing analysis. Future studies are also likely to yield significantly lower photon costs as a result of technological advances which directly affect the laser; examples of these are improvements in efficiency, and engineering developments which eliminate high cost and/or limited lifetime components.

In the midst of these cost estimates, it is well to consult the experience of laser manufacturers. Considerable experience has been accumulated for $\mathrm{CO}_{2}$ and excimer lasers in industrial marking. Znotins of Lumonics Inc. has developed cost estimates for a $200 \mathrm{~Hz}, 50 \mathrm{~W}$, industrial excimer laser operated for eight hours per day over a 10,000 hour operational lifetime. ${ }^{15}$ The costs are $\$ 100, \$ 30$ and $\$ 200$ per $\mathrm{kWh}$ for capital, operating and maintenance charges respectively. These various cost estimates are combined in Table II which also shows costs for two wavelengths from medium pressure metal vapour lamps. ${ }^{1}$

The wide variation in the values entered in this table highlights the state-of-development of laser technology. Clearly not only must laser chemical processes be developed but the lasers to implement this processing must also be developed. Progress will be greater if these developments are made in tandem. This state of affairs is often known

Table II Cost estimates for various light sources. ${ }^{a}$

\begin{tabular}{lrll}
\hline Source & $\lambda / \mathrm{nm}$ & $\begin{array}{l}\text { Integrated costs/ } \\
\$ / 1 \mathrm{kWh}(\$ / \text { Einstein })\end{array}$ & Reference \\
\hline AVLIS-dye & $\approx 600$ & $36-360(2-20)$ & 10 \\
$\mathrm{KrF}^{\mathrm{b}}$ & 248 & $330(50)$ & 15 \\
$\mathrm{KrF}$ & 248 & $34(5)$ & 11,12 \\
$\mathrm{KrF}$ & 248 & $14(2)$ & 16 \\
$\mathrm{CO}_{2}{ }^{\mathrm{c}}$ & 10,000 & $11(0.04)$ & 11,12 \\
$\mathrm{CO}_{2}$ & 10,000 & $1.7(0.006)$ & 16 \\
$\mathrm{XeCl}_{\mathrm{CO}_{2}{ }^{\mathrm{c}}}$ & 308 & $250-500(30-60)$ & 14 \\
$\mathrm{Hgd}_{\mathrm{Tgl}}$ & 10,000 & $140(0.50)$ & 14 \\
$\mathrm{Hg}^{\mathrm{d}}$ & 535 & $0.25(0.016)$ & 1 \\
\hline
\end{tabular}

${ }^{a}$ Cost estimates as developed in cited studies. Costs in each study use different assumptions for cost inputs and different costing scenarios.

${ }^{b}$ Industrial excimer costs.

c TEA laser, d $60 \mathrm{~kW}$ thallium doped medium pressure mercury lamp.

e $60 \mathrm{~kW}$ medium pressure mercury lamp.

${ }^{\mathrm{f}}$ Cost developed for wavelengths in the range $290-310 \mathrm{~nm}$. 
as a chicken and egg situation; no one is sure which will come first. Few organizations are able to fund this dual track development; few processes of themselves offer sufficient incentive. The rewards for laser chemistry development are in the breadth rather than the strength of applications. Governments clearly have an important role here and it is to be hoped that the laser development lessons learned in classified, laser enrichment programs are gradually released to a wider audience. ${ }^{17}$

\subsubsection{Cost implications}

Given the magnitude of the estimates presented above we are drawn to several inescapable conclusions. To be economic laser processes must use every laser photon in an efficient manner. Lasers can only be used to drive stoichiometric reactions if the product is of extremely high value. Bulk chemicals can only be produced via non-stoichiometric processes. These include; (1) removal of low concentration contaminants; (2) free radical chain reactions; (3) homogeneous photopolymerization; and (4) laser generation of unique catalysts with high turnover rates.

To illustrate the inappropriateness of lasers for production of bulk chemicals produced by stoichiometric reactions let us consider the following example researched by ICI in the mid 1970's. ${ }^{18}$ Tetrafluoroethylene is required for Teflon production. As it may polymerize explosively it is made on site in fairly small, dedicated plants. These plants produce $\mathrm{C}_{2} \mathrm{~F}_{4}$ by heating freon- $22\left(\mathrm{CF}_{2} \mathrm{HCl}\right)$. However, there are extensive side reactions which are limited by running the reaction to only $40 \%$ conversion and operating a $2.5 x$ recycle loop. Even this strategy gives a product which contains a broad spectrum of compounds. These must be separated in an expensive and energy wasteful separation plant. Thus, $\mathrm{C}_{2} \mathrm{~F}_{4}$ is a fairly expensive, bulk chemical valued at $50 \mathrm{c} / \mathrm{lb}$, let us say $10 \mathrm{c} \mathrm{mole}^{-1}$. The IR laser photodissociation of freon-22 is a reasonably efficient process giving $\mathrm{C}_{2} \mathrm{~F}_{4}$ and $\mathrm{HCl}$ as unique products. This is a clear advantage over bulk heating. However, to eliminate $\mathrm{HCl}$ we have to provide approximately $2.3 \mathrm{eV}$ to each molecule. Taking the most optimistic cost of $\mathrm{CO}_{2}$ laser photons from Table I $(\$ 1.7 / \mathrm{kWh})$, we find that the IR photodissociation process working at unit thermodynamic efficiency would produce $\mathrm{C}_{2} \mathrm{~F}_{4}$ with an associated laser cost of $21 \mathrm{c} \mathrm{mole}^{-1}$. Clearly, we cannot use this 
process to produce $\mathrm{C}_{2} \mathrm{~F}_{4}$ at $10 \mathrm{cmole}-1$, better to produce carbon- 13 at $10^{5} \mathrm{c} \mathrm{mole}^{-1} .^{14}$

In the following sections we consider the progress made in laboratories around the world in the use of lasers to produce high valued products and to drive non-stoichiometric reactions.

\subsection{Laser isotope separation}

Interest in laser isotope separation techniques was spurred by the following considerations. Uranium nuclear fuel has a value of $\$ 1000$ $\mathrm{kg}^{-1}$ for a uranium-235 enrichment of $3 \%$ (from a $0.7 \%$ natural abundance). ${ }^{19}$ The current market is in the range $\$ 10^{9}$ to $\$ 10^{10}$ per year. ${ }^{19}$ For historical reasons, uranium enrichment processes are compared in terms of separate work units (SWU).

$$
\text { No. of SWU }=\frac{[(2 w-1) \ln 450 \cdot 712 w+450 \cdot 710(w-t)]}{1-w}
$$

where $w$ is the weight fraction of uranium-235 in the product stream and $t$ is the weight fraction in the waste stream..$^{20}$ For the present example $t=0.002138, W=0.03$, which implies 10.04 SWU per kg. Recent estimates suggest $1 \mathrm{SWU}$ requires $2400 \mathrm{kWh}$, electrical energy. ${ }^{21} \mathrm{~A} 1 \mathrm{~kg}$ product stream requires $5.7 \mathrm{~kg}$ natural uranium. With uranium costs at $\approx \$ 100 \mathrm{~kg}^{-1}$ and electrical costs at 36 mil per $\mathrm{kWh}$, the requirement for a more efficient separation scheme is obvious.

In the early 70's various alternate enrichment processes were developed for uranium. Two laser processes gained prominence. Atomic vapour laser isotope separation (AVLIS) involves selective ionization of uranium vapour via sequential resonant excitation to the ionization continuum using dye lasers. ${ }^{22}$ Molecular laser isotope separation (MLIS) involved infrared multiphoton dissociation (IR MPD) of uranium hexafluoride via sequential excitation of molecular vibrations using $\mathrm{CO}_{2}$ and frequency-shifted $\mathrm{CO}_{2}$, lasers. ${ }^{23}$ Following a period of intense research and development, the AVLIS process was chosen for pilot plant scale development at the Lawrence Livermore National Laboratory. Recently, similar decisions have been taken in the UK (British Nuclear Fuels) and are pending in France and Japan.

Uranium AVLIS promises to be the first viable process using laser chemistry processing. This has come about because of an integrated 
and intensive technology development of both the chemical process and the required laser systems. ${ }^{17,21}$ Much of this development has occurred in US government laboratories. In order to underline the interrelationship between process and laser development, we will highlight aspects of uranium AVLIS available from the open literature. We will then consider aspects of MLIS necessary to assess the viability of other laser isotope separation schemes. We will then consider several promising opportunities for laser isotope separation for specific elements.

\subsubsection{Atomic vapour isotope separation}

The AVLIS process involves isotopically selective ionization of uranium vapour. The atomic spectroscopy suggests the use of multiple frequencies in the $2 \mathrm{eV}$ region. Level lifetimes suggest the use of reasonably short pulses $(20 \sim 200 \mathrm{~ns})$ at reasonably high energy densities $\left(10^{-1} \mathrm{~J} \mathrm{~cm}^{-2}\right)$ to achieve saturated excitation. The doppler width, hyperfine structure and isotope shift of atomic transitions suggest that laser bandwidths of $1 \mathrm{GHz}$ are adequate. Similarly, frequency stabilities of $\sim 100 \mathrm{MHz}$ are required. The vapour flow rate achieved by electron beam heating of uranium metal, and the requirement to illuminate all vaporized atoms suggest laser repetition frequencies of $10^{4} \mathrm{~Hz}$. With the benefit of hindsight, it is easy how these requirements suggested the development of copper vapour laser pumped dye lasers from laboratory curiosities to integrated systems capable of high average power output. ${ }^{17}$ The status of the program at Lawrence Livermore National Laboratories has recently been summarized: ${ }^{17}$

This equipment has been operated for several years in a fully integrated system capable of producing up to five precision $( \pm 30 \mathrm{MHz})$ frequency beams and a total visible power of 50-100 W tunable. Based upon this success, we are now proceeding to the construction of a system which will be able to operate continuously throughout the year with the same number of frequencies (and control) at a total visible power level of 1000-10,000 W tunable. It will be the penultimate coherent light source, and due to its extremely high degree of coherence at these high powers, it is in our view a true 'laser' that found an application!

We note that this entirely admirable situation has been reached only with the commitment of hundreds of people. It does indicate that practical laser chemistry applications can be developed, but only if both the chemical and laser technology are developed concomitantly and only if the economic incentives are sufficiently great to support the 
development costs involved. It is to be hoped that the successful implementation of the AVLIS process will have numerous positive implications for laser chemistry applications in the private sector.

\subsubsection{Molecular laser isotope separation}

In molecular laser isotope separation laser radiation illuminates a chamber containing two isotopomers ${ }^{i} A$ and ${ }^{j} A$ and causes a photochemical transformation such that

$$
\begin{aligned}
{ }^{i} A & \rightarrow{ }^{i} B ; k_{i} ; n_{i} \\
{ }^{j} A & \rightarrow{ }^{j} B ; k_{j} ; n_{j}
\end{aligned}
$$

$k_{i}, k_{j}$ are the specific rates constants for reactions $I$ and $J, n_{i}\left(n_{j}\right)$ is the number of photons absorbed per molecule of ${ }^{i} B\left({ }^{j} B\right)$ produced. If the intrinsic isotopic selectivity $\alpha={ }^{i} A k_{i} /{ }^{j} A k_{j}$ ) is not equal to unity then the isotopic ratio in the tails of the reactions $\left(\beta={ }^{i} A_{t}{ }^{j} A_{t}\right)$ evolves as $\beta=$ $m \exp \left(k_{j}(1-\alpha) t\right)$, where $t$ represents time or pulse index and $m$ represents the starting isotopic ratio $\left(m={ }^{i} A / j A\right)$. In this example, the fractional abundance of ${ }^{j} A$ clearly increases to the limit 1 with time. At the same instance the isotopic ratio in the product (heads) stream $\left({ }^{i} B_{t} /{ }^{j} B_{t}\right)$ evolves as $m\left(1-\exp \left(-\alpha k_{j} t\right)\left(1-\exp \left(-k_{j} t\right)^{-1}\right.\right.$; that is, from an initial value $m \alpha$ to a final value $m$. From these simple considerations most aspects of MLIS economics can be obtained. In particular to be economic, processes with high $\alpha$ and low $n_{j}$ values are required, especially when $m$ is small.

\subsubsection{Deuterium}

Large quantities of deuterium, as heavy water are required for cooling thermal neutron reactors, in for example the CANDU (CANadian Deuterium Uranium) system. This need is currently met by the efficient Girder-Sulphide chemical exchange process. Laser isotope separation of deuterium has been a subject of intense investigation in many parts of the world. The low natural abundance of deuterium $\left(1.4 \times 10^{-4}\right)$ establishes two stringent requirements for any laser process:

(1) The working molecule must be water or methane or must exchange hydrogen with either of these molecules in a rapid and efficient process. 
(2) The absorption selectivity must be in the range $10^{3}$ to $10^{4}$.

Many otherwise reasonable laser processes have been abandoned as they fail to meet these criteria.

Two laser processes remain under active investigation: (1) IR MPD of $\mathrm{CF}_{3} \mathrm{D}^{24}$; and, (2) IR MPD of $\mathrm{CFDCl}_{2} .{ }^{25}$ The former process has been actively developed in the USA and the latter in China and Switzerland. The characteristic properties of the two methods have been compared in a recent paper by Zhang Linyang et al. ${ }^{25}$ They conclude that the most serious drawback to the $\mathrm{CF}_{3} \mathrm{D}$ process is its slow rate of exchange with water, whereas the $\mathrm{CFDCl}$ process is hampered by lower operating temperatures $(200 \mathrm{~K})$ and pressures (10 mbar). It is the opinion of this author that the low natural abundance of deuterium and the high working fluences and low working pressures required by both processes $\left(\mathrm{CF}_{3} \mathrm{D}, 20 \mathrm{~J} \mathrm{~cm}^{-2}, 2 \mathrm{~ns}\right.$ pulse length, $130 \mathrm{mbar} ; \mathrm{CFDCl}_{2}$, $7 \mathrm{~J} \mathrm{~cm}^{-2}, 100 \mathrm{~ns}$ pulse length, $10 \mathrm{mbar}$ ) set unreasonable requirements for long pathlength high intensity interaction regions $\left(\mathrm{CF}_{3} \mathrm{D}, 120 \mathrm{~m}\right.$; $\left.\mathrm{CFDCl}_{2}, 1000 \mathrm{~m}\right) \cdot{ }^{25}$ The $\mathrm{CF}_{3} \mathrm{D}$ process has been characterized for 10 $\mathrm{R} 26$ and the $\mathrm{CFDCl}_{2}$ process at $10 \mathrm{P} 38$. Neither of these are the line of choice for high average power, high wall plug efficiency $\mathrm{CO}_{2}$ laser design.

The question of long pathlength interaction with resonant absorbers, at IR energy densities in the range $10 \mathrm{~J} \mathrm{~cm}^{-2}$, has yet to be adequately addressed in the literature. Yet, it is an issue of crucial importance to MLIS processes. Clearly conventional multimode $\mathrm{CO}_{2}$ lasers which operate on high order spatial modes, randomly determined by gain competition from pulse to pulse, will be inferior in this respect to single spatial mode oscillators. This is a consequence of both the inherent pointing jitter of the laser and of non-linear interactions and refractive index changes as the beam propagates through the medium. However, single spatial mode oscillators have the following disadvantages: (1) the energy extraction efficiency is usually lower and (2) the fluence across the beam radius is not constant. Since most MLIS parameters ${ }^{26}$ are strongly fluence dependent this presents a severe problem.

It is possible that hybrid oscillator amplifiers could be developed to overcome these limitations and it is likely that phase conjugate reflection processes will have a crucial role. However, for the moment the issue remains almost unaddressed. In closing this section we note that 
there is a serious oversupply of heavy water (Canadian heavy water production capacity $\approx 10^{9} \mathrm{~g}$ per year) and that the Canadian government is mothballing excess capacity. In light of this economic reality it is unlikely that MLIS of deuterium will be actively pursued.

\subsubsection{Tritium}

Heavy water is used as a coolant and moderator in natural-uranium, thermal-neutron reactors. As a consequence, there is a natural build up of tritium in such reactors. This presents both a problem and an opportunity. The tritium must be removed as it presents a health hazard, primarily to reactor workers; but, it could also be used to fuel future fusion reactors. Tritium separation units installed on CANDU reactors use hybrid technology (hydrogen/liquid water exchange via Combined Electrolysis and Catalytic Exchange (CECE), and Liquid Phase Catalytic Exchange (LPCE) in conjunction with final enrichment by cryogenic distillation of liquid hydrogen) which cost in the neighbourhood of $\$ 60 \times 10^{6}$ per unit.

Tritium has been separated from deuterium by various MLIS processes. Herman and coworkers at LLNL have pioneered the IR MPD of $\mathrm{CTCl}_{3}$ using an optically $\left(\mathrm{CO}_{2}\right)$ pumped $\mathrm{NH}_{3}$ laser ${ }^{27}$ and Makide, Takeuchi et al. have developed the IR MPD of $\mathrm{CTF}_{3}{ }^{28}$ and $\mathrm{C}_{2} \mathrm{~F}_{5} \mathrm{~T}^{29}$ using $\mathrm{CO}_{2}$ lasers. I have introduced the concept of using frequency doubled $\mathrm{CO}_{2}$ lasers to directly pump carbon-tritium bonds at $5 \mu \mathrm{m} .{ }^{30}$ This concept will gain acceptance as efficient doubling media (silver gallium sulphide and silver gallium selenide) become available. ${ }^{31}$

\subsubsection{Carbon-13}

I have recently reviewed current use and production of carbon-13 and I quote from this review. ${ }^{14}$

Carbon-13 occurs in nature at a natural abundance of $1.11 \%$. In current commercial production it is enriched to $90 \%$ by the low temperature distillation of carbon monoxide. Carbon-13 is used as a tracer. It finds applications in disciplines ranging through medicine, agriculture, chemistry, nutrition and environmental science. Single experiments may consume spectacular quantities of the isotope; for instance, air transport tests involve the release of 100 gram quantities of methane-21, ${ }^{13} \mathrm{CD}_{4}$. However, overall demand for the isotope is not large. The global consumption in 1981 was approximately $5 \mathrm{~kg}$ at a price of US $\$ 70$ per gram.

It is believed that the largest opportunity for increased use of carbon-13 lies in the development of routine medical applications such as breath tests and whole body nmr. 
Of these two applications breath tests are the furthest developed. Breath tests are non-invasive medical tests which measure the rate of metabolism by monitoring the rate of appearance of isotopically labelled carbon dioxide following ingestion of an aliquot of a specific, isotopically labelled substrate. It has been little over a decade since carbon isotope breath tests provided information not easily gathered by other techniques. Thus in 1971, it was shown that the rate of deconjugation of bile acids could be measured by observing labelled carbon dioxide production following ingestion of cholylglycine labelled with carbon-14. As a consequence the extent of bacterial overgrowth in the large intestine could be determined. Labelled compounds have since been applied to the study of many conditions in humans as shown in Table III.

Both carbon-13 and carbon-14 labelled compounds have been used in breath tests. Isotope ratio mass spectroscopy and radiocarbon counting are the respective analytical methods. The use of carbon-13 is obviously preferred for small children and pregnant women. Moreover, there is growing non-acceptance of the proliferation of carbon-14 use in hospitals because of the hazards and costs associated with storage and disposal of wastes. We estimate, using reasonable projections for carbon-13 detection costs that carbon-14 tests would also be significantly more expensive to administer.

Is is thought that the diagnosis of three gastrointestinal disorders presents the most significant opportunity for carbon-13 breath tests. These are liver disfunction, fat malabsorption and bacterial overgrowth in the large intestine. Liver disfunction may be diagnosed by many tests including biopsy. However the non-surgical methods are generally unsatisfactory in diagnosing the early stages of liver disorder. Often the liver appears to function normally until it is $70-80 \%$ functionally destroyed; at this point, little may be done. Liver disease is a major cause of North American mortality. For these reasons the aminopyrine breath test may become the most frequently used of the

Table III Functions studied by carbon isotopes and substrates used. ${ }^{\mathrm{a}}$

\begin{tabular}{ll}
\hline Function studied & Substrate used \\
\hline Carbohydrate malabsorption & \\
$\quad$ Lactose deficiency & Lactose \\
Sucrose-isomaltase deficiency & Sucrose \\
Fat malabsorption & Trioctanoin \\
Malabsorption screening & Triolein \\
& Tripalmitin \\
Ileal dysfunction and bacterial overgrowth & Glycocholate \\
& Glucose \\
Hepatic dysfunction & Aminopyrene \\
& Phenancetin \\
& Galactose \\
Drug metabolism & Caffeine \\
Inborn errors of metabolism & Diazepam \\
& Laevodopa \\
Carbohydrate metabolism & Glycine \\
\hline
\end{tabular}

${ }^{a}$ From reference 14. 
carbon-13 tests. The diagnosis of fat malabsorption is relatively straightforward. Precise quantities of fat are ingested by the patient and his faeces are analysed for undigested fat; this procedure is objectionable enough to make the trioctanoin/triolein breath tests attractive. Furthermore, in Europe the test is administered with patients confined to hospital for several days. The breath test could be administered on an outpatient basis which would result in considerable savings to central health care agencies. Bacterial overgrowth in the large intestine is currently studied by similar methods which could be replaced by the glycocholate/glucose breath test. All these tests are at the research and development state and presently use only some grams of carbon-13 per year. However, clinical trials have been initiated and estimates of the mature world market potential for carbon-13 range upwards to $200 \mathrm{~kg}$ per year.

I have also reviewed progress in laser isotope separation of carbon13 up until the end of $1984 . .^{32}$ In summary there are two viable processes under active investigation. (1) IR MPD of freon-22 $26,33,34$ and (2) IR MPD of $\mathrm{CF}_{3} \mathrm{Br}$ and/or $\mathrm{CF}_{3} \mathrm{I}^{35}$ In laboratory scale up studies of the trifluoro methyl halide process a sophisticated, high-repetition rate $\mathrm{CO}_{2}$ laser capable of kilowatt output powers was used together with a complex irradiation cell and gas recycling system. Specifically, it was reported that carbon- 12 at $99.99 \%$ carbon- 12 content could be produced at $1 \mathrm{gh}^{-1}$, using $360 \mathrm{~W}$ average power, by the infrared multiphoton dissociation of ${ }^{13} \mathrm{CF}_{3} \mathrm{I}$ in natural trifluoromethyl iodide. ${ }^{35,36}$ Production rates for enriched carbon- 13 were not reported in this study. However for $\mathrm{CF}_{3} \mathrm{Br} / \mathrm{O}_{2}$ mixtures, the reported energy expenditures of $150 \mathrm{eV}$ per atom at $30 \%$ carbon- 13 content are clearly inferior to the results of a scale up study of the freon-22 process which show $\varepsilon$ values of around $20 \mathrm{eV}$ per atom at $50 \%$ carbon- 13 content. ${ }^{26} \mathrm{It}$ was also reported that $150 \mathrm{~W}$ average power irradiations of ${ }^{13} \mathrm{CF}_{3} \mathrm{I}$ in natural trifluoromethyliodide gave $0.48 \mathrm{gh}^{-1}$ carbon at $12.4 \%$ carbon13 content, as $\mathrm{C}_{2} \mathrm{~F}_{6} \cdot{ }^{37}$

The freon-22 process appears to have superior characteristics. A laboratory scale up using unmodified commercial equipment and feedstock has been described. ${ }^{26}$ An initial study of the effect of fluence, laser frequency, freon-22 pressure and pressure of argon, nitrogen and trifluoromethyl chloride was made in short, irradiation cells (constant fluence) in order to define optimum process parameters. The process was then scaled to higher throughput in longer cells $(1-5 \mathrm{~m})$ in which compensation for beam-energy depletion by absorption was made by reduction in the beam area by focussing. From the scale-up experiments, measurements of yield and enrichment of the tetrafluoroethylene product gave demonstrated production rates. These, coupled with measurements of the absorption, allowed extrapolation to pro- 
duction rates assuming total utilization of the available output energy. Using a $100 \mathrm{~W}$ TEA CO 2 laser $\left(10^{*} \mathrm{~J}, 10 \mathrm{~Hz}\right)$ we have demonstrated production rates of $0.20 \mathrm{gh}^{-1}$ carbon- 12 at $99.99 \%$ carbon- 12,11 $\mathrm{mgh}^{-1}$ carbon- 13 at $72 \%$ carbon- 13 and $10 \mathrm{~kg}$ per annum carbon- 13 at $50 \%$. Energy absorption measurements imply a capability to produce $3 \mathrm{~kg}$ per annum carbon-13 at over $95 \%$ carbon-13 in a two-stage process. The apparatus was used to produce gram quantities of carbon-13 deleted freon-22 (99.99\% carbon-12).

Detailed engineering descriptions and process costs have been developed for this method and for several alternates. These include: low temperature distillation of carbon monoxide, which is current commercial practice; two chemical exchange methods, both gas-liquid and liquid-liquid; a single photon photolysis scheme, based upon photolysis of single rovibronic levels of formaldehyde using a injection-locked, line narrowed, $\mathrm{XeCl}$ excimer laser; and various combinations of laser chemistry and conventional enrichment technologies.

Capital and operating costs for the chemical plant and laser facilities were developed for plant sizes of $100 \mathrm{~kg}$ per annum and estimates for plant sizes of $50 \mathrm{~kg}$ and $10 \mathrm{~kg}$ per annum were factored from this base. These costs were input into a typical chemical industry, financial model to develop selling and break-even prices. The sensitivity of these prices to variations in rates of production, capital costs, operating costs, labour costs and operating strategy were developed. The results show that the two stage infrared laser chemistry process provides the lowest cost product up to production rates of $50 \mathrm{kgm}$ per annum. However, the cost differentials are such that other considerations such as state of development of the process or process operating characteristics could favour other methods.

In this regard it is worth noting that the two stage laser route is not a mature process as is the current technology. Therefore, there is still the opportunity to improve the laser process by further research. We illustrate this point by the following comparison. We have demonstrated production rates of $10 \mathrm{~kg}$ per annum of $50 \%$ carbon- 13 using a $10 \mathrm{~Hz}$ laser at $10 \mathrm{~J}$ per pulse. With this same laser energy it would be possible to produce $160 \mathrm{~kg}$ per annum of pure carbon-13 if selectivities and process kinetics were improved!

Since my 1985 review there have been two significant developments in laser isotope separation of carbon-13. Arai and co-workers have 
demonstrated selective production of ${ }^{13} \mathrm{CF}_{3} \mathrm{Br}$ by IRMPD of $\mathrm{C}_{2} \mathrm{~F}_{6} / \mathrm{Br}$ mixtures $^{38}$ and Letokhov's group at the Institute of Spectroscopy USSR have demonstrated that multiple-frequency IRMPD of freon22 gives increased extent of dissociation at high carbon-13 selectivities. ${ }^{39}$ Whether these two inventions have practical significance for carbon-13 production or whether the increased process complexity precludes their implementation remains to be seen.

\subsubsection{Silicon-30}

Elemental silicon contains three isotopes silicon-28, silicon-29 and silicon-30 in the ratio 92.23:4.67:3.10. The later may be converted to phosphorous-31 by neutron irradiation. Were this process carried out using crystalline silicon one would produce a phosphorous doped silicon lattice without the damage to the crystalline structure produced by conventional ion implantation. ${ }^{40}$ Clearly this semiconductor material would be expensive and would only be used where extremely high reliability and/or low incorporation of redundant circuits were required. Such applications include whole-wafer integration and satellite components. ${ }^{40}$

Arai's group at the Institute of Physical and Chemical Science, Tokyo has succeeded in producing $\mathrm{SiF}_{4}$ containing $6 \%$ silicon-29 and $46 \%$ silicon-30 following IR MPD of 2 torr natural $\mathrm{Si}_{6} \mathrm{~F}_{6}$ using the $10 \mathrm{P} 14$ at $0.36 \mathrm{~J} \mathrm{~cm}{ }^{-2}{ }^{41}$ The low value of the working fluence, a consequence of the weak $\mathrm{Si}-\mathrm{Si}$ bond and the strong IR absorption band, is extremely encouraging for future scale up of this process to high production rates.

It will be of great interest to see if the techniques of laser microchemistry ${ }^{8}$ and isotopically selective IR MPD can be combined to give direct epitaxial deposition of silicon-30. However, the experimental challenges to achieving this goal are no doubt severe.

\subsubsection{Zirconium-91}

The CANDU nuclear reactor uses zirconium metal in construction of its in-core parts; the calandria, pressure tubes and fuel cladding. A $550 \mathrm{MW}$ CANDU reactor requires $30 \mathrm{Mg}$ zirconium for its construction. Zirconium is a refractory metal (M.P. $2125 \mathrm{~K}$ ) with a low absorption cross-section for thermal neutrons. This cross-section could be considerably reduced by the use of zirconium-91 depleted 
material (Table IV) as the neutron capture by zirconium-91 is an order of magnitude greater than for all other isotopes.

The costs associated with the isotopic depletion could be recovered by any of several specific design advantages. The most obvious is the reduction in fuelling costs associated with the increased burn up possible. This of course applies more to the permanent reactor components (calandria and pressure tubes) than to the fuel cladding. Allowable costs are $\$ 3000 / \mathrm{kg}$ and $\$ 100 / \mathrm{kg}$ respectively. ${ }^{42}$ Secondly, one could use thicker more durable pressure tubes less susceptible to failure. The allowable costs of avoiding a retubing outage 16 years hence implies a present value of $\$ 5000 / \mathrm{kg}$. Other disadvantages for reactors designed using isotopically depleted zirconium are the possibility of higher temperature annealing of thicker pressure tubes to produce tubes with lowered radiation induced growth and the possibility of increased pressure and temperature for thicker tubes leading to improved overall thermodynamic efficiency for the power generating cycle. ${ }^{43}$ Finally, we note that improved design flexibility could have beneficial impact on the Thorium-232/Uranium-233 fuel cycle.

The potential fueling savings using zirconium-91 depleted material have been known for some time. ${ }^{44}$ However, the topic gathered increased momentum with the catastrophic failure, under load, of a pressure tube in Pickering Unit 2 in August 1983. Several approaches to zirconium-91 depletion are under active research in Canada; chemical exchange, ion cyclotron resonance, MLIS and AVLIS. We at NRC have been carrying out the AVLIS work and have recently had some encouraging results. ${ }^{45}$

Table IV Zirconium isotopic data.

\begin{tabular}{lllll}
\hline $\begin{array}{l}\text { Mass } \\
\text { number }\end{array}$ & $\begin{array}{l}\text { Natural } \\
\text { abundance } \%\end{array}$ & $\begin{array}{l}\text { Thermal neutron } \\
\text { absorption } \\
\text { cross-section }(\mathrm{mb})\end{array}$ & $\begin{array}{l}\mathrm{a} \\
\lambda / \mathrm{nm}\end{array}$ & $\begin{array}{l}\mathrm{b} \\
\alpha\end{array}$ \\
\hline 90 & 51.46 & 14.4 & 613.6241 & 100 \\
91 & 11.23 & 1360 & 613.6231 & 100 \\
92 & 17.11 & 180 & 613.6244 & 100 \\
94 & 17.40 & 50 & 613.6247 & 100 \\
96 & 2.80 & 21 & 613.6249 & 100 \\
\hline
\end{tabular}

\footnotetext{
a Dye laser wavelength for selective AVLIS, from reference 45 and 46.

b Minimum observed selectivity for photoionization of particular isotopes, from reference 45 .
} 
At first glance one would be foolish to attempt AVLIS for zirconium. This is because zirconium lies in the middle of the periodic table and here isotope shifts are vanishingly small. However zirconium is element 40 , an even number of protons and zirconium- 91 is the only naturally occurring isotope with an odd number of neutrons. All even, even isotopes have zero nuclear spin. Thus, the expected structure for atomic zirconium transitions is a central clump due to all isotopes with lines from zirconium-91 removed from this as a consequence of hyperfine interactions. Therefore, selective excitation of zirconium-91 was a reasonable expectation.

This expectation was confirmed in a high resolution study of a supersonic zirconium beam produced by laser vaporization of a zirconium metal rod. ${ }^{46}$ We have also been able to resolve the hyperfine splitting in the upper state via quantum beat spectroscopy. ${ }^{47}$

Excitation of the first resonant transition $\left[\left(4 \mathrm{~d}^{2} 5 \mathrm{~s}^{2}\right) \mathrm{a}^{3} \mathrm{~F}_{2} \rightarrow\right.$ $\left.\left(4 \mathrm{~d}^{2} 5 \mathrm{~s} 5 \mathrm{p}\right) \mathrm{z}^{3} \mathrm{~F}_{2}{ }^{\circ}\right]$ at $613.6 \mathrm{~nm}$, followed by absorption of a $308 \mathrm{~nm}$ photon ( $\mathrm{XeCl}$ laser) absorbed in a resonant manner gives efficient ionization. Tuning the red photon gives selective ionization for all isotopes. ${ }^{45}$ Precise wavelengths and minimum measured selectivities are given in Table IV. The maximum selectivity measurable with our apparatus (a consequence of signal-to-noise considerations in our time-of-flight mass spectrometer) was 100 .

Thus, we have demonstrated scientific viability for zirconium AVLIS, a situation reached for uranium in 1973. Zirconium AVLIS and uranium AVLIS have many interesting similarities. Both elements are refractory, reactive materials, both have resonance transitions in the red and both have ionization potentials in the $6.6 \mathrm{eV}$ range. For zirconium, the hyperfine splitting is greater than the isotope shift, for uranium the opposite is true. Thus, zirconium AVLIS is far more challenging. The economic incentive for zirconium enrichment is intimately linked to the degree of uranium enrichment in the reactor fuel. Utilities may opt for an enrichment technology with the flexibility to address both issues.

\subsubsection{Mercury-196}

In an earlier section of this review we called attention to the use of mercury-196 in mercury-197 production. This application presents at best a small scale requirement. Recently, a high volume application for 
mercury-196 has been suggested. ${ }^{49}$ Common fluorescent lamps use a weakly ionized plasma in rare gases $(1$ Torr $)$ and mercury $\left(6 \times 10^{-3}\right.$ Torr). The conversion of electrical energy to $253.7 \mathrm{~nm}$ radiation is extremely high (55 to $65 \%) .{ }^{2}$ This efficiency is limited by resonance trapping which effectively increases the lifetime of the emitting state allowing increased opportunity for quenching reactions. Maya and co-workers of the Lighting Products division of GTE have demonstrated that lamps operating on mercury in which the 196 isotopic concentration was increased from 0.146 percent (natural abundance) to 4.6 per cent were $5 \%$ more efficient. ${ }^{49}$ They note that

Accurate electrical and temperature measurements indicate that no significant changes would have to be made in the ballast, fixture, and lamp impedance design to accommodate this innovation.

\section{Further}

Annual consumption of electrical energy for fluorescent lighting in the United States is about $1.8 \times 10^{11} \mathrm{kWh}$. If 50 percent of the market converted to the new technology (a conservative estimate), savings, at $5 \notin$ per kilowatt-hour, would total $\$ 200$ million annually. As fluorescent lamps penetrate the residential market, the ultimate savings in energy costs may greatly exceed this figure.

To date, allowable costs for this isotope separation have not been developed. Given the efficiency and availability of monoisotopic mercury resonance lamps, it is unlikely that narrow linewidth lasers operating at $253.7 \mathrm{~nm}$ will offer viable production alternatives; however, this does not totally exclude laser participation in alternate or hybrid enrichment technologies.

\subsubsection{Thallium-203/201}

Thallium-203, a stable, naturally occurring isotope of thallium with a natural abundance of $29.5 \%$ is used in the production of thallium-201 by the following series of reactions:

$$
{ }^{203} \mathrm{Tl}(p, 3 n) \longrightarrow{ }^{201} \mathrm{~Pb} \stackrel{\beta-}{\longrightarrow}{ }^{201} \mathrm{Tl}
$$

The resulting radioactive thallium-201 is then injected into patients as thallium chloride, where by means of transaxial emission tomography it can be used in diagnosis to differentiate between true myocardial infarcts ("heart attacks") and myocardial insufficiency.

Enriched thallium-203 for use as a spallation targets is produced by the calutrons at Oak Ridge and sells for $\$ 2000$ per gram $(\$ 406,000$ per 
mole!). Despite this, demand remains strong as (i) very small amounts of thallium-201 are required per patient, making the unit cost of the procedure acceptable, (ii) the procedure is regarded as a very useful technique in a life threatening medical area. In 1983, 600 grams of thallium-203 were sold by Oak Ridge for a gross revenue of $\$ 1.2 \mathrm{M}(\mathrm{US})$. As with all pharmaceuticals the cost of materials is a small component of the selling price. Thus, the costs of thallium-201 on a molar basis are astronomical!

There are several opportunities for AVLIS to make an impact upon this market sector. ${ }^{50}$ They are:

(i) Preparing target materials of single stable isotopes;

(ii) Re-enriching the target materials after cyclotron irradiation;

(iii) Enriching the thallium-201 produced by cyclotron irradiation.

The latter two processes will require the development of micro-scale AVLIS, well within the bounds of commercially available laser and materials handling technologies.

\subsection{Laser synthesis of fine chemicals}

Having dealt with laser production of isotopes we now turn to opportunities open in the production of other fine chemicals. Again, before considering any future role that lasers may have it is well to consider some current realities of the pharmaceutical industry. Drugs are expensive and rigourously controlled. It has been estimated that it costs of the order of $£ 20 \times 10^{6}$ to bring a new drug to market. ${ }^{51}$ This is a result of the costs of the $R \& D$ and extensive test procedures that any new drug made by a particular protocol must be subjected to. Manufacturers then are necessarily reluctant to replace approved production protocols by new, improved, laser methods. This large initial investment forms part of the production cost which in turn makes up $30 \%$ of the selling price. Marketing (25\%), testing (15\%), profit, administration and taxes (30\%) make up the remaining $70 \%$.

From this brief and indefinite analysis of the pharmaceutical industry we can form some definite opinions of the role of laser. Lasers can only enter this market through the research and development laboratories. It must be established that lasers offer organic chemists a variety of rapid, efficient, high yield, synthetic routes. Once this has been demonstrated, the capital cost of the laser equipment will provide 
only a small impediment, witness the number of multinuclear nmr machines installed in organic chemistry departments. ${ }^{19}$ Following the routine use of lasers in the research department we can expect the caveat expressed earlier concerning the displacement of elegant photochemical methods by multistep conventional routes to apply. However, as the requirements for selective excitation and reaction specificity become more stringent one may expect the photochemical and laser methods to retain their role through to the final production protocols. This is not to assert that lasers provide the only elegant and selective synthetic methods (the chimeric "laser surgery" or "bond selective" myths). Indeed, we take the position that the most elegant and selective syntheses were carried out, not by physical chemists, but by microorganisms!

In what follows we consider the use of lasers in selective organic photochemistry highlighting the opportunities for improved synthetic methods.

\subsubsection{Carvone photochemistry}

The photolysis of carvone (I) a conjugated cyclic ketone to yield carvone camphore (II) a saturated tricyclic ketone has been studied for many years (the original work being done on the roof of Bologna University). ${ }^{52}$ In addition, a third product (III) 1-exo-5-dimethyl-synethoxycarbonyl methylbicyclo [2.1.1] hexane results from photoaddition of the solvent (ethanol). We have investigated the details of the laser photochemistry of this molecule. ${ }^{53}$ The results are summarized in Table V. It can be seen that by judicous choice of laser one can tailor the product distribution to yield essentially pure II or III. This is

Table V Products of carvone photolysis ${ }^{\mathrm{a}}$.

\begin{tabular}{lccc}
\hline Laser $(\lambda / \mathrm{nm})$ & III & II & Product $^{\mathrm{b}}$ \\
& & I \\
\hline YAG E 3(355) & 2.3 & 96.1 & 1.6 \\
$\mathrm{XeF}(351)$ & 2.1 & 94.4 & 3.5 \\
$\mathrm{Kr}^{+}(351,356)$ & 9.3 & 81.7 & 9.0 \\
XeCl(308) $_{\text {Sunlight }}{ }^{\mathrm{c}}$ & 98 & 0 & 2 \\
& 0 & 9 & 91 \\
\hline
\end{tabular}

\footnotetext{
a After reference 53 .

b See text

c Reference 52.
} 
because II absorbs at $308 \mathrm{~nm}$ and not $350 \mathrm{~nm}$ allowing smooth transformation to III if a $\mathrm{XeCl}$ laser is used. Pulsed lasers at $350 \mathrm{~nm}$ can intercept triplet $I$ and reduce its opportunity to react with solvent, according to the following mechanism:

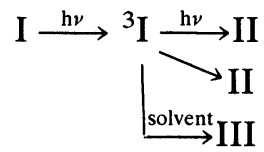

$$
\begin{aligned}
& >10^{-3} \\
& 10^{-3} \\
& 5 \times 10^{-5}
\end{aligned}
$$

\section{Quantum Yield}

These results clearly establish two advantages. Lasers provide convenient sources of monochromatic light allowing selective excitation and pulsed lasers allow access to the photochemistry of transient species ( ${ }^{3} \mathrm{I}$ has a lifetime of $75 \mathrm{~ns}$ in ethanol).

\subsubsection{Vitamin-D}

Our studies of the laser photochemistry of 7-dehydrocholesterol establish another advantage of selective excitation: the ability to break photochemical equilibria. ${ }^{3}$ We have recently reviewed this area and I quote from this review: ${ }^{54}$

Vitamin-D is responsible for the proper regulation of bone growth in humans. It is produced in vivo by the action of sunlight on cholesterol in this skin. The process proceeds with great specificity. Lack of vitamin-D leads to a number of disorders the most widely known being rickets, a disease prevalent among the general population during the industrial revolution. Adequate public health measures now provide protection to the majority of the population against the deficiency, however, synthetic vitamin-D is required as an additive to dairy products for human consumption and as an additive to animal feed. Supplements of vitamin-D are particularly important in livstock production involving battery breeding stations, for instance chicken production, where the animal is kept in the dark or under artificial light for the majority of its lifetime. The photochemical process retains its role in industrial production despite poor yields. The isomers 7-deohydrocholesterol, lumisterol pre-vitamin and tachysterol all have a triene chromophore and all absorb in the near UV.

Havinga and co-workers have reported on the details of the vitamin-D photochemical system. ${ }^{53}$ These quantum yields, together with the absorption spectra of the four isomers and the spectral distribution of the light source can be used to predict the composition of the photostationary state: some examples are shown in Table VI. In essence then current industrial methodology involves tailoring the light source and irradiation time to maximize the conversion of 7-dehydrocholesterol to pre-vitamin-D. As only previtamin-D offers biologically active material it must be separated from the other isomers. This has been accomplished in a number of ways one of which is derivatization followed by fractional crystallization. This separation stage obviously introduces extra cost into the process, moreover, the process is obviously inefficient as not all of the 7 -dehydrocholesterol is converted to pre-vitamin-D. Yields are typically $40 \%$. Our initial work on the laser photochemistry of 7-dehydrocholesterol was reported in $1981 .^{3}$ 
In this work, we reported that the photostationary state obtained in photolysis of the pro-vitamin by light from a $\mathrm{KrF}$ or $\mathrm{XeCl}$ laser was essentially identical to that predicted by Havinga et al. ${ }^{55}$ However, we were able to recognize a little serendipity: (1) the KrF photostationary state is predominantly tachysterol; (2) the absorption spectrum of tachysterol is significantly red-shifted from all other isomers; and (3) tachysterol is smoothly converted, albeit with less than ideal quantum yield, into pre-vitamin-D. Thus, we expect that two colour irradiation of pro-vitamins with $\mathrm{KrF}$ followed by light in the $350 \mathrm{~nm}$ region would yield a photostationary state high in pre-vitamin-D. This was confirmed by experiments reported in Table VI.

The immediate implications of this work for industrial production of vitamin-D are straightforward. The $\mathrm{KrF}$ photolysis state can be replaced by the cheap, efficient, reliable, spectrally pure low pressure mercury lamp at $254 \mathrm{~nm}$. The second stage may be effected by a suitably filtered medium pressure mercury lamp. Vitamin-D produced by this dual wavelength photolysis route will be sufficiently active $(28,000,000$ I.U./gm) for use in animal feed without additional purification. Moreover, additional production facilities could be upgraded simply by adding the second photolysis stage to convert useless tachysterol into potentially active pre-vitamin-D.

Table VI Composition of the photochemistry state in the vitamin-D production. ${ }^{\text {a }}$

\begin{tabular}{lcccl}
\hline Light source & $\% 7-\mathrm{DHC}$ & $\% \mathrm{~T}_{3}$ & $\% \mathrm{~L}_{3}$ & $\% \mathrm{P}_{3}$ \\
\hline Low pressure $\mathrm{Hg}$ & 1.5 & 75 & 2.5 & 20 \\
Medium pressure $\mathrm{Hg}$ & 3.4 & 26 & 17 & 53 \\
$\mathrm{KrF}$ laser & 2.9 & 71 & & 26 \\
$\mathrm{XeCl}$ laser & 13.0 & 3.4 & 42 & 35 \\
$\mathrm{KrF}+\mathrm{N}_{2}$ laser & 0.1 & 11 & 9 & 80 \\
\hline
\end{tabular}

${ }^{a}$ After reference 3.

\subsubsection{Hydroxy vitamin-D}

We, in collaboration with workers from the Endocrine Research Unit of the Mayo Clinic Foundation, ${ }^{56}$ and others ${ }^{57}$ have shown that the two wavelength laser photolysis scheme can be used to maximize yields in the synthesis of hydroxy-derivatized vitamin-Ds. Vitamin-D is not in fact a vitamin. It is more a hormone, metabolic function being controlled by the $1 \alpha, 25$-dihydroxy-vitamin. This material is produced via the kidney and liver. People unable to metabolize vitamin-D suffer osteodistrophy and in these cases the synthetic hydroxy-vitamin is a potent corrective agent.

\subsubsection{Vitamin $\mathrm{K}$ trioxane}

R. Marshall Wilson has used laser selective photochemistry to prepare these materials from vitamin $\mathrm{K}^{58}$ As in the carvone example, the photolysis product may absorb a second photon $(\lambda \nless 410 \mathrm{~nm})$ from an 
unfiltered source and undergo secondary photolysis to give cleavage products. Only by using a monochromatic argon-ion laser $(\lambda \approx 450 \mathrm{~nm})$ could useful quantities of the trioxane be isolated.

\subsubsection{Prostaglandins}

Prostaglandins play important roles in biochemistry. For instance, prostaglandin endoperoxide is transformed into both thromboxane which causes the aggregation of blood platelets and prostacyclin which inhibits the aggregation. These modes of action are of critical importance to modern medicine, particularly for the success of artificial implants. However these substances are extremely unstable and their interconversions are not understood. R. Marshall Wilson has successfully synthesized single side chain analogues of prostaglandin endoperoxide using laser initiated trapping of biradicals produced from "reluctant" bicycloazoalkanes. ${ }^{59}$

\subsection{Laser driven non-stoichiometric reactions}

Lasers have had significant success in initiating chain reactions and preparing homogeneous photocatalysts. Some examples are detailed below.

\subsubsection{Vinyl chloride}

Wolfrum has made extensive studies of this problem. ${ }^{60} \mathrm{I}$ quote from Richard Hall's review of this work:

They studied the synthesis of vinyl chloride $\left(\mathrm{C}_{2} \mathrm{H}_{3} \mathrm{Cl}\right)$ from dichloroethane $\left(\mathrm{C}_{2} \mathrm{H}_{4} \mathrm{Cl}_{2}\right)$ using a $\mathrm{KrF}$ lasers to produce $\mathrm{C}_{2} \mathrm{H}_{4} \mathrm{Cl}$ and $\mathrm{Cl}$ radicals. At the conventional process operating temperature of $500^{\circ} \mathrm{C}$ they are able to increase the product yield to $75 \%$ (from $60 \%$ ) while maintaining the selectivity for producing $\mathrm{C}_{2} \mathrm{H}_{3} \mathrm{Cl}$ versus other products at $85 \%$. The quantum yield observed at $500^{\circ} \mathrm{C}$ is approximately 20,000 . Using the laser and lowering the operating temperature to $300^{\circ} \mathrm{C}$, they increased the selectivity to $99 \%$ while maintaining the product yield achieved without the laser at $500^{\circ} \mathrm{C}$. The quantum yield at the lower temperature is about 5000 . The energy required to generate the $\mathrm{KrF}$ laser photons is only $6 \%$ of the energy required to heat the dichloroethane from 300 to $500^{\circ} \mathrm{C}$. Similar laser-assisted syntheses have been investigated with certain fluoro-chlorocarbons that seem to be promising candidates for a laser-based process. The value of such products is roughly 20 times that of vinyl chloride and the industrial demand for teflon-like materials remains high. ${ }^{11}$

The process is being tested at the pilot plant level on an arm of vinyl chloride production plant. ${ }^{61}$ 


\subsubsection{Ethyl bromide}

Reddy and Zavelovich have been able to demonstrate chain lengths of over $10^{4}$ in the production of ethyl bromide, an additive to leaded petroleum, by photolysis of $\mathrm{HBr}$ /ethylene mixtures using a $\mathrm{XeF}$ excimer laser. ${ }^{62}$ They attribute the long chain lengths to homogeneous initiation via two photon photolysis of $\mathrm{HBr}$. Current commercial practices involves $\gamma$ ray irradiation using a cobalt source. Clearly introduction of this promising technology has much to do with the future of leaded gasoline.

\subsubsection{Cumene hydroperoxide}

Cumene hydroperoxide is an intermediate used in the production of acetone and phenol. It is produced by thermal autooxidation of cumene. Bray and Chou have demonstrated that a XeF laser at $351 \mathrm{~nm}$ enhances the rate of this process and reduces the induction period. ${ }^{63}$ Clark, Stevens and Perettie have studied a similar process and conclude that the photoinitiated chain reaction has significant advantages over the purely thermal process, including fewer side products and higher rate. ${ }^{64}$ They feel though that a large scale process would use metal doped lamps rather than lasers.

\subsubsection{Methyl chloride}

K. V. Reddy has demonstrated quantum yields in excess of $10^{4}$ for photo chlorination of methane. ${ }^{16}$ This is pioneering work directed to finding new sources of ethylene.

\subsubsection{Photocatalysis}

The use of lasers to generate hetero- and homogeneous catalysts is an area of active research beyond the scope of this review. The reader is referred to papers presented at a recent SPIE conference for details. ${ }^{65}$

\section{CONCLUSIONS}

Lasers will find a role in the future production of expensive materials. Uranium nuclear fuel prepared by the AVLIS process should be 
available in the early 1990's. Carbon-13 can be most efficiently produced by the MLIS process; significant production rates have been demonstrated using commercially available equipment and feedstocks. If the demand expands as a result of general implementation of medical breath tests one can expect tht the MLIS process will be given serious economic consideration. MLIS looks to be attractive for other isotopes e.g. silicon and tritium. The picture is not so bright for deuterium however. Research in deuterium MLIS was accelerated in the early 1970's when the forecast Canadian annual demand for heavy water was: dependable, $3400 \mathrm{Mg}$; probable, $4090 \mathrm{Mg}$ and optimistic, $4450 \mathrm{Mg} .{ }^{66}$ To this we should add: actual, $1200 \mathrm{Mg}$. All MLIS production units will face the critical design question: Is it better to develop interaction regions based upon single spatial mode output ("gaussian" beam profile) or multimode output ("top-hat" profile)? More research is needed here.

We should expect AVLIS production methods to spread to other isotopes. Mercury, zirconium and plutonium are prime candidates. There is a definite need for the technological development of microscale AVLIS units to be used in conjunction with (medical) cyclotron, radioisotope production. This will present some interesting but not insurmountable challenges and will lead to some strong markets. It will also provide a much improved product.

Lasers are so clearly superior in initiating non-stoichiometric reactions that it is inevitable that they find a role here. However much remains to be improved in the area of laser reliability before this happens.

Lasers offer very significant advantages for organic synthesis and we are confident that their use in research laboratories will spread. R. Marshall Wilson writes that organic photochemists are reluctant to adopt lasers as they require UV light source with average powers of at least 100 milliwatts and in order to achieve full spectral coverage two or three laser systems are required. Clearly laser manufacturers have been in a position to meet this requirement for some years. Along with the development of reliable, multiwavelength UV lasers we should give some consideration to simple reaction cell design. It is only through this route that lasers will eventually find their way into fine chemical production, as they inevitably will.

Much has been ignored in this review. The areas of laser microchemistry, laser materials processing, laser production of catalysts, laser 
purification, laser photopolymerization and laser production of ceramics have received only cursory mention in order to be able to dwell upon direct laser production of chemicals. Much has beem made of the chicken and egg dichotomy and in this regard the cartoon presented in Figure 1 is appropriate. This anonymous, untitled work has been in the photochemistry laboratories at NRC since the time of E. W. R. Steacie. I am sure it has inspired many practising photoche-

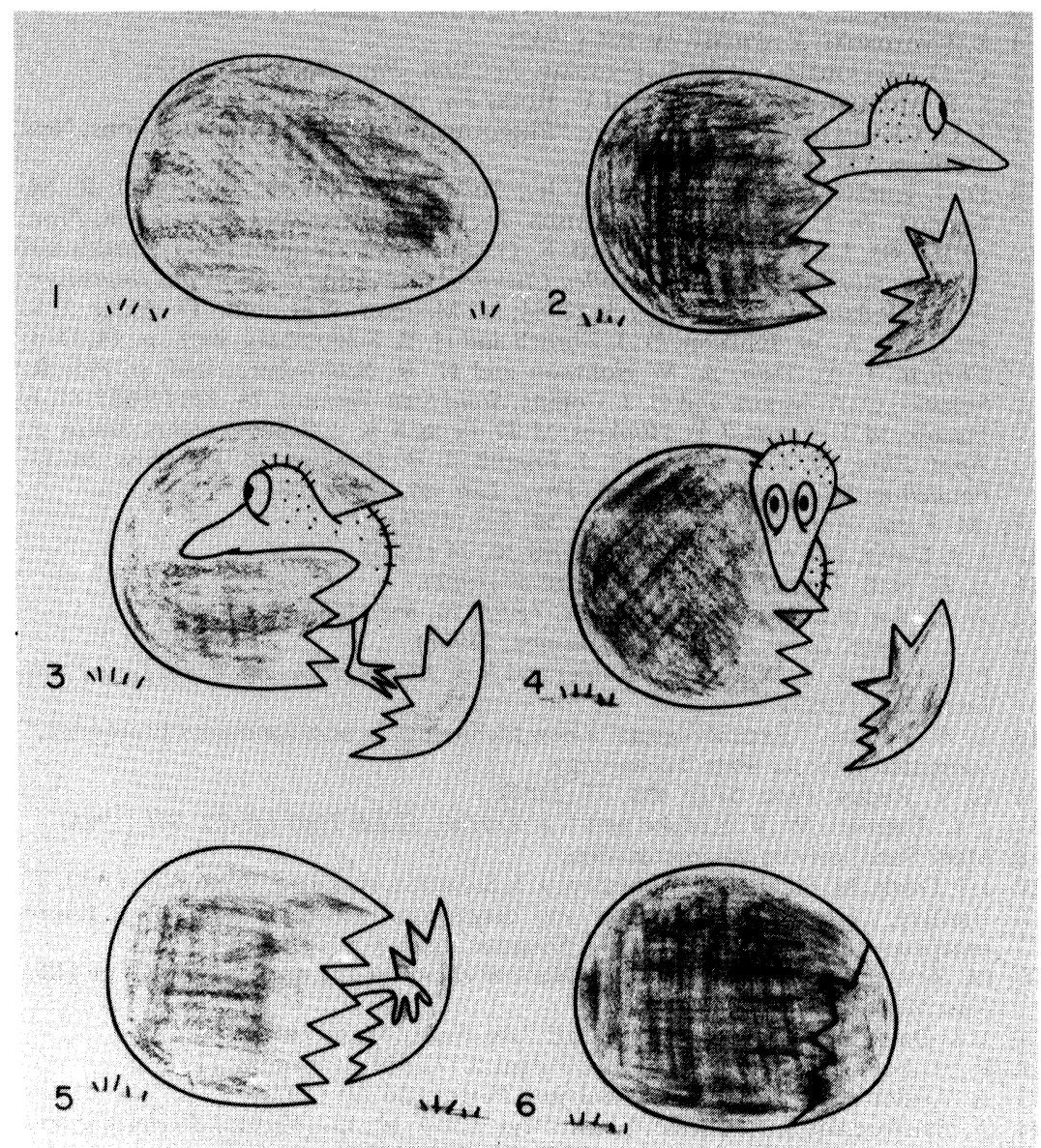

Figure 1 The problem with all emerging technologies ... 
mists. The role of those who work in the area of developing reliable laser chemistry processes or in developing reliable lasers is to make sure that the chicken stays out of the egg; once this happens, the questions which came first will be irrelevant.

\section{References}

1. M. Fischer, Agnew. Chem. Int. Ed. 17, 16 (1978) and references cited therein.

2. M. Koedam, A. A. Kruithoff and J. Riemans, Physica 29, 565 (1963).

3. V. Malatesta, P. A. Hackett and C. Willis, JACS 103, 6781 (1981).

4. S. Mrozowski, Z. Physik 78, 8źó (1932).

5. C. G. McDonald and G. E. Gunning, J. Chem. Phys. 20, 1817 (1952).

6. J. P. Morand, M. Waconge and E. Roth, En. Nucl. 10, 362 (1968).

7. J. G. Calvert and J. N. Pitts., Jnr., "Photochemistry," John Wiley and Sons, New York, p. 119 (1966).

8. D. J. Ehrlich and R. M. Osgood, Jr., Thin Solid Films 90, 287 (1982); R. M. Osgood, D. J. Ehrlich, T. F. Deutsch, D. J. Silversmith and A. Sanchez, Proc. SPIE. 385, 112 (1983); M. L. Lloyd, K. G. Ibbs, A. W. Johnson, D. J. Ehrlich and H. R. Schlossberg, Laser Controlled Chemical Processing of Surfaces Symposium, North Holland, New York, p. 36 (1984; M. Meunier, J. H. Flint, D. Alder, J. S. Haggerty, A. W. Johnson, D. J. Ehrlich and H. R. Schlossberg, ibid., p. 14; D. J. Ehrlich, T. Y. Tsao, A. W. Johnson and H. R. Schlossberg, ibid, p. 195; R. Solanki, C. A. Moore and G. J. Collins, Solid State Technol. 28, 220 (1985); G. J. Fisanik, M. E. Gross, J. B. Hopkins, M. D. Fennell, K. J. Schnoes and A. Katzir, J. Appl. Phys. 57, 1139 (1985); G. J. Fisanik, J. B. Hopkins, M. E. Gross, M. D. Fennell and K. J. Schnoes, Appl. Phys. Lett. 46, 1184 (1985).

9. M. Klein, Ann. Rev. Phys. Chem. 36, 525 (1985).

10. J. I. Davis, IEEE Trans. Nuc. Sci. NS-30, 24 (1983).

11. R. B. Hall, Laser Focus, 57, September (1982).

12. A. Kaldor and R. L. Woodin, Proc. IEEE 70, 565 (1982).

13. S. L. Ream, Laser Focus, 46, December (1982).

14. P. A. Hackett, C. Willis, M. Gauthier and A. J. Alcock, Proc. Int. Conf. Lasers, 481 December (1983).

15. T. A. Znotins, "Excimer lasers: a new technology in semiconductor processing," submitted to Solid State Technology.

16. K. V. Reddy, Proc. SPIE 458, 53 (1984).

17. J. L. Emmett, W. F. Krupke and J. I. Davies, IEEE JQE QE-20, 591 (1984).

18. Mary Sime, private communication.

19. J. I. Davis, M. Field, C. P. Robinson, J. I. Steinfeld, N. Turro, W. S. Watt and J. T. Yardley, "Laser photochemistry and diagnostics, recent advances and future prospects." Report on NSF, DOE Seminar, June 4-5 (1979).

20. M. Bennedict and T. H. Pigford, "Nuclear chemical engineering." McGraw-Hill, New York, p. 403 (1957).

21. J. I. Davis and R. W. Davis, AIChE Sym. Series 73, 69 (1977).

22. R. H. Levy and G. S. Janes, U.S. Patent 3,772,519, November (1973).

23. A. Kaldor and P. Rabinowitz, Belgium Patent 846,225 (1975).

24. A. Hartford and S. A. Tuccio, Chem. Phys. Letters 60, 431 (1979); I. P. Herman and J. P. Marling, Chem. Phys. Letters 64, 75 (1979).

25. A. Hansen, P. Gogel, H. van den Bergh, Helv. Phys. Acta 55, 187 (1982). 
26. Zhang Linyang, Zhang Yunwu, Ma Xingxiao, Yuan Peng, Xu Yan, Gong Mengxiong and W. Fuss, Appl. Phys. B39, 117 (1986).

27. R. Magnotta, I. P. Herman and F. T. Aldridge, Chem. Phys. Letters 92, 600 (1982).

28. K. I. Takeuchi, I. Inoue, R. Nakane, Y. Makide, S. Kato and Y. Tominaga, J. Chem. Phys. 76, 398 (1982).

29. Y. Makide, S. Kato, Tominaga and K. Takeuchi, Appl. Phys. B32, 33 (1983).

30. M.-K. Au, P. A. Hackett, M. Humphries and P. John, Int. J. Laser Chem. 4, 275 (1983).

31. R., L. Beyer, private communication.

32. P. A. Hackett, Rev. Laser Eng. 13, 12 (1985).

33. M. Gauthier, C. G. Cureton, P. A. Hackett and C. Willis, Appl. Phys. B28, 43 (1982).

34. M. Gauthier, A. Outhouse, Y. Ishikawa, K. O. Kutschke and P. A. Hackett, Appl. Phys. B35, 173 (1984).

35. V. Yu. Baranov, IEEE JQE QE-19, 1577 (1983).

36. O. N. Avatkov, A. B. Bakhtadze, V. Yu Baranov, V. S. Dolojikov, E. G. Gverdtsiteli, S. A. Kazakov, V. S. Letakhov, V. C. Pismmenyi, E. A. Ryabov and V. M. Vetsko, Appl. Opt. 23, 26 (1984).

37. G. I. Abduchelishvili, O. N. Avatkov, V. N. Bagratashvili, V. Yu. Baranov, A. B. Bakhtadze, E. P. Velikov, V. M. Vetsko, I. G. Kolomiiskii, V. S. Letokhov, S. V. Pigul'skii, V. D. Pis'mennyi, E. A. Ryabov, G. I. Tkeshelashvili, Sov. J. Quantum. Electron. 12, 459 (1982).

38. S. Arai, T. Watanabe, Y. Ishikawa, T. Oyama, O. Hayashi and T. Ishii, Chem. Phys. Letters 112, 224 (1984).

39. A. V. Evseev, V. S. Letokhov and A. A. Puretzky, Appl. Phys. B36, 93 (1985).

40. Terry Gough, private communication.

41. M. Kamioka, S. Arai, Y. Ishikawa, S. Isomura and N. Takamiya, Chem. Phys. Letters 119, 357 (1985).

42. K. B. Woodall, Ontario Hydro Report 84-306-K, p. 25 (1984).

43. C. J. Simpson, Ontario Hydro Report 84-306-K, p. 8 (1984).

44. R. DeWitt, Mound Laboratories Report, MLM-2391, January 21 (1977).

45. M. R. Humphries, O. L. Bourne and P. A. Hackett, Chem. Phys. Letters 118, 134 (1985).

46. O. L. Bourne,M. R. Humphries, S. A. Mitchell and P. A. Hackett, Opt. Commun. 56, 403 (1986).

47. D. M. Rayner and P. A. Hackett, work in progress.

48. S. A. Tuccio, J. W. Dubin, O. G. Peterson and B. B. Snavely, IEEE JQE QE-11, 1010 (1975).

49. Y. Maya, M. W. Grossman, R. Lagushenko and J. F. Waymouth, Science 226, 435 (1984).

50. P. A. Hackett and C. Willis, Consultants meeting on recent advances in isotope separation, IAEA, Vienna, NRC Report No. C1091-825, September (1979).

51. Roger Newton, private communication.

52. G. Ciamician and P. Silber, Chem. Ber. 41, 1928 (1908).

53. V. Malatesta, C. Willis and P. A. Hackett, J. Org. Chem. 47, 3117 (1982).

54. P. A. Hackett, C. Willis, M. Gauthier and A. J. Alcock, Proc. SPIE 458, 65 (1984).

55. E. Havinga, Experientia 29, 1181 (1973) and references cited therein.

56. V. Malatesta, V. Solan and P. A. Hackett in "Photochemistry and photobiology: proceedings of the international conference," Vol. II, ed. A. H. Zewail (Harwood Academic Publishers, Chur, Switzerland, 1983) p. 857.

57. W. G. Dauben and R. B. Phillips, JACS 104, 858 (1982).

58. R. M. Wilson, T. F. Walsh and S. K. Gee, Tetrahedron Letters 1, 3459 (1980). 
59. R. M. Wilson, Proc. SPIE 458, 58 (1984); W. Adam, K. Hannemann and R. M. Wilson, JACS 100, 7647 (1984); W. Adam, K. Hannemann, E. M. Peters, K.

Peters, H. G. von Schnering and R. M. Wilson, Angewandte Chemie 97, 417 (1985).

60. J. Wolfrum, Umschau 84, 480 (1984); J. Wolfrum, Proc. SPIE 458, 46 (1984).

61. J. Wolfrum, private communication.

62. K. V. Reddy and J. Zavelovich, Lasers '85, Las Vegas, paper HQ5.

63. R. G. Bray and M. S. Chou, Proc. SPIE 458, 75 (1984).

64. J. B. Clark, J. C. Stevens and D. J. Perettie, Proc. SPIE 458, 82 (1984).

65. R. L. Woodin and A. Kaldor, ed. "Applications of lasers to industrial chemistry," Proc. SPIE 458, 119-159 (1984).

66. L. R. Haywood and P. L. Lamb, Chemistry in Canada 19, March (1975). 